\title{
Quality criterion to optimize separations in capillary electrophoresis: Application to the analysis of harmala alkaloids
}

\author{
Marcos Tascon ${ }^{\mathrm{a}, \mathrm{b}}$, Fernando Benavente ${ }^{\mathrm{b}}$, Cecilia B. Castells ${ }^{\mathrm{a}}$, Leonardo G. Gagliardi ${ }^{\mathrm{a}, *}$ \\ a Laboratorio de Investigación y Desarrollo de Métodos Analíticos, LIDMA and División Química Analítica Facultad de Ciencias Exactas, UNLP-CONICET, \\ Calle 47 esq. 115, La Plata B1900AJL, Argentina \\ ${ }^{\mathrm{b}}$ Departament de Química Analítica, Facultat de Química, Universitat de Barcelona, Barcelona, Spain
}

\section{A R T I C L E I N F O}

\section{Article history:}

Received 30 March 2016

Received in revised form 7 July 2016

Accepted 13 July 2016

Available online 14 July 2016

\section{Keywords:}

Capillary electrophoresis

Optimization

Quality criteria

Harmala alkaloids

\begin{abstract}
A B S T R A C T
In capillary electrophoresis (CE), resolution $\left(R_{S}\right)$ and selectivity $(\alpha)$ are criteria often used in practice to optimize separations. Nevertheless, when these and other proposed parameters are considered as an elementary criterion for optimization by mathematical maximization, certain issues and inconsistencies appear. In the present work we analyzed the pros and cons of using these parameters as elementary criteria for mathematical optimization of capillary electrophoretic separations. We characterized the requirements of an ideal criterion to qualify separations within the framework of mathematical optimizations and, accordingly, propose: -1- a new elementary criterion ( $\left.t^{\prime}\right)$ and -2- a method to extend this elementary criterion to compose a global function that simultaneously qualifies many different aspects, also called multicriteria optimization function (MCOF).

In order to demonstrate this new concept, we employed a group of six alkaloids with closely related structures (harmine, harmaline, harmol, harmalol, harmane and norharmane). On the basis of this system, we present a critical comparison between the new optimization criterion $t$ ' and the former elementary criteria. Finally, aimed at validating the proposed methods, we composed an MCOF in which the capillaryelectrophoretic separation of the six model compounds is mathematically optimized as a function of $\mathrm{pH}$ as the unique variable. Experimental results subsequently confirmed the accuracy of the model.
\end{abstract}

(c) 2016 Published by Elsevier B.V.

\section{Introduction}

The development of an analytical separation method typically requires an optimization of the conditions [1-4]. First, the aspects of the analysis that will be optimized must be defined and these aspects constitute, conceptually, the desirability or the optimization quality and/or qualification criterion $(Q C)$. The definition of the $Q C$ should be designed according to the manner of optimization-i.e., a maximization, minimization, or a definition of acceptability limits. The QCS depend on operational variables (OVs), which can be discrete, such as the chemical nature of the background electrolyte (BGE) or type of additive, or continuous such as $\mathrm{pH}$, temperature, or the concentration of components in the separation medium [5]. A given $Q C$ can be a very simple concept, with a clear and understandable physical meaning-such as selectivity $(\alpha)$, resolution $\left(R_{S}\right)$, analysis time $\left(t_{a n}\right)$, and limit of detection (LOD)-or can also involve

\footnotetext{
* Corresponding author.

E-mail addresses: leogagliardi@quimica.unlp.edu.ar, leogagliardi@fcnym.unlp.edu.ar (L.G. Gagliardi).
}

a complex function [6-8]. Furthermore, in certain instances, more than one aspect can be optimized simultaneously (i.e., multiobjective or multicriterion optimizations) [5,9]. This situation obtains when the aim is to optimize the separation of several compounds, i.e. the optimization is based on many $\alpha$ or $\mathrm{R}_{\mathrm{s}}$ between all the pairs of compounds. Once all the QCs and OVs have been defined, a number of exploratory experiments are required to acquire real information about the system, in order to fit mathematical equations to the real values, to then interpolate or extrapolate those discrete observations, and finally to find the $O V$ leading to the best possible $Q C$. In one case, mathematical expressions used to fit the experimental results can be empirical and thus require a significant number of experiments to accurately establish the real dependencies of the QCs on the OVs. In the opposite case, the equations can have a sound basis in models derived from solid theories. Those equations require a reduced number of exploratory experiments for obtaining satisfying expressions describing the behaviors of the $Q C$ over wide ranges of the OVs so as to enable even extrapolations.

In chromatography, the separation between pairs of compounds is adequately characterized by $R_{S}$. The use of the $R_{S}$ as the QC has been implemented in many optimization software programs 
[10-13]. Nevertheless, in CE, the number of phenomena affecting the peak widths and peak shapes are greater than in chromatography, thus requiring a large number of exploratory experiments in order to predict $R_{S}$ [8-10]. Alternatively, other QCs could be used to describe the separation between analytes. In general, QCs based on mobilities offer the advantage that the dependence of that parameter on the different $\mathrm{OVs}$ becomes more predictable. As a result, the number of required experiments can be reduced significantly yielding favorable consequences in terms of optimization time, reduction of chemical waste, and operational costs $[6,14,15]$. This is the case when the $O V$ to optimize is $\mathrm{pH}$, a variable affecting directly the ionization of weak acids or bases [16]. The dependencies of effective mobilities on $\mathrm{pH}$ are well known, and expressions relating those two parameters can be easily deduced [2,3,17-19]. Different parameters have been proposed as $Q C$ for optimizing CE separations using $\mathrm{pH}$ as the $\mathrm{OV}$. Giddings postulated an early definition of selectivity $(p)$, including a difference of velocities $(\Delta U)$ between the pair of ions under consideration and their average velocity $(U)$ [20]:

$p=\frac{\Delta U}{\bar{U}}$

Later, Gebauer and Boček defined an analogous expression, but based on mobilities $(\mu)$ instead of velocities [16],

$p=\frac{\Delta \mu}{\bar{\mu}}$

Both expressions can be interconverted by taking into account the electric field, E $(U=\mu \mathrm{E})$. Selectivity between a pair of compounds $\left(\alpha_{i j}\right)$ is nowadays [6] defined as the ratio of their effective mobilities $\left(\mu_{\text {eff }}\right)$ :

$\alpha_{i j}=\frac{\mu_{e f f, i}}{\mu_{e f f, j}}$

where $\mu_{\text {eff }, i}>\mu_{e f f, j}$. This definition is algebraically analogous to the one used in chromatography. A relevant difference exists, however, when $\alpha$ is used as a $Q C$ for separation optimization in chromatography vs. CE, principally related to the domains of the retention factors $\left(k_{i j}\right)$ and $\mu_{\text {eff }}$. The $k_{i j}$ values can range from virtually zero-i.e., the void volume marker-up to infinity for any compound fully retained in the stationary phase. Moreover, based on physical fundamentals, $k_{i j}$ is often modeled as a logarithm, under which the $Q C-O V$ relationships are usually linear or, at least, smooth for mathematical optimization by maximization or minimization. In contrast, $\mu_{\text {eff, }}$ values can range from certain discrete positive numbers-i.e., the $\mu_{\text {eff, }}$ of the hydrogen ion-to other discrete negative numbers-i.e., the $\mu_{\text {eff, }}$ of the hydroxyl ion. Furthermore, many analytes, such as those used in this study, are uncharged within significant zones of the $\mathrm{OV}$ domains-e. $g$., at isoelectric points or pHs more than 2 units away from the $p K a$ values. Since inversions in the migration order and reversal of the migration direction are frequent, those changes necessitate a redefinition of $\alpha$ over the OV scales, resulting in discontinuities and nonderivable points-all of which features constitute drawbacks to mathematical optimizations. These explanations based on the selectivity definition exemplify the importance of a proper definition of $Q C$ in determining the success of mathematical optimization. With respect to $\mathrm{CE}$ the following considerations must be taken into account:

-1- QCs must be mathematically monotonous over the whole range even when the order of migration between analytes changes. For instance, this issue is relevant to any QCs involving a mobility difference that is positive by definition, or involving a quotient such as $\alpha_{i j}$, which must be $>1$ by definition.

-2- QC must likewise be monotonous when the mobility of one analyte changes its sign. In general, this situation occurs with QCS



Fig. 1. Basic $\beta$-carboline structure of the harmala alkaloids (HAlks). Table 1 lists the substituents R1 and R2 and the presence of unsaturation.

given as a multiplication or quotient, such as $\alpha_{i j}$ as a function of $\mathrm{pH}$ around an isoelectric point.

-3- QC must give the same weight to the separations over the entire $O V$ domain and specifically must not approach to infinite when the mobility of one analyte approaches zero. For example, an extreme situation is the co-migration of the slower analyte with all the neutral substances, always present in real samples. The presence of neutral species requires that $C E$ takes into consideration the mobility of all those uncharged species (along with the EOF markers and solvent peaks) as an additional peak from which the analyte peaks should be separated.

Some of these optimization issues have been identified in the early $80^{\prime} \mathrm{s}$. In an attempt to overcome those problems, Jorgenson and Lukacs included the EOF in the denominator of their definition of selectivity (pí) [5]:

$p_{i j}^{\prime}=\frac{\mu_{i}-\mu_{j}}{\mu_{E O F}+\mu_{j}}$

where $\mu_{i}>\mu_{j}$. Eq. (4), although, is an incomplete solution because the denominator can still become zero. Furthermore, the inclusion of $\mu_{E O F}$ confers on pí a dependence on a property having a known variability that depends on the material of the capillary wall and changes with the physical and chemical properties of the BGE [21-24].

In 1994, B.K. Clark et al. proposed the use of the difference between the effective mobilities of the analytes being considered, $d_{i j}[25]$ :

$d_{i, j}=\mu_{e f f(i)}-\mu_{e f f(j)}=\Delta \mu_{i, j}$

where $\mu_{\text {eff }, i}>\mu_{\text {eff }, j}$. This definition overcomes the mathematical drawback of ratios becoming infinite when denominators approach zero, although, $d_{i j}$ still retains the shortcomings of changes in migration order and also can give false optimum values that fail to become separated from neutral species.

In this work, we propose an alternative criterion to qualify the separations in CE. Our aim was to develop the simplest mathematical function that would overcome all the aforementioned difficulties. We also describe how to compose a multicriterion function based on an elementary $Q C$ that allow a true mathematical optimization in the separation of more than two compounds. The theoretical prediction based on this novel criterion was tested by optimizing the separation of six harmala alkaloids (HAlks) (harmine, harmaline, harmol, harmalol, harmane and norharmane) as a function of $\mathrm{pH}$. These compounds share a $\beta$-carboline structure (see Fig. 1) and differ only in either one functional group or an unsaturation (Table 1). This similarity in the charge/mass ratio between those analytes makes their separation a relevant analytical challenge [26-29]. 
Table 1

Properties of harmala alkaloids (Halk): side-chain moieties, presence of unsaturations (C3-C4, marked in Fig. 1 ), molecular mass molecular mass, and $p K_{\mathrm{a}}$.

\begin{tabular}{|c|c|c|c|c|c|c|c|c|c|}
\hline \multirow[t]{2}{*}{ HAlk } & \multirow[t]{2}{*}{$-\mathrm{R}_{1}$} & \multirow[t]{2}{*}{$-R_{2}$} & \multirow[t]{2}{*}{ Bond $\left(C_{3}-C_{4}\right)$} & \multirow[t]{2}{*}{$\mathrm{M}(\mathrm{Da})$} & \multicolumn{2}{|l|}{$p K \mathrm{a}_{1}$} & \multicolumn{2}{|l|}{$p K \mathrm{a}_{2}$} & \multirow[t]{2}{*}{ Ref. } \\
\hline & & & & & Experimental & Literature & Experimental & Literature & \\
\hline 1.Harmine & $-\mathrm{CH}_{3}$ & $-\mathrm{OCH}_{3}$ & Double & 212.1 & $7.85( \pm 0.06)$ & 7.45 & - & - & \\
\hline 2.Harmaline & $-\mathrm{CH}_{3}$ & $-\mathrm{OCH}_{3}$ & Single & 214.1 & $9.6( \pm 0.1)$ & 9.55 & - & - & \\
\hline 3.Harmane & $-\mathrm{CH}_{3}$ & $-\mathrm{H}$ & Double & 182.1 & $7.5( \pm 0.1)$ & 7.34 & - & - & \\
\hline 4.Norharmane & $-\mathrm{H}$ & $-\mathrm{H}$ & Double & 168.1 & $7.10( \pm 0.06)$ & 6.76 & - & - & \\
\hline 5.Harmalol & $-\mathrm{CH}_{3}$ & $-\mathrm{OH}$ & Single & 200.0 & $8.25( \pm 0.05)$ & 8.62 & $11.3( \pm 0.1)$ & 11.30 & \\
\hline 6.Harmol & $-\mathrm{CH}_{3}$ & $-\mathrm{OH}$ & Double & 198.1 & $7.72( \pm 0.05)$ & $7.86,7.90$ & $9.52( \pm 0.07)$ & $9.51,9.47$ & [36] \\
\hline
\end{tabular}

\section{Experimental}

\subsection{Instrumentation}

All the experiments were performed on a Lumex Capel 105M CE system, with UV detector (Lumex Ltd., St. Petersburg, Russia). Measurements of $\mathrm{pH}$ were made with a Crison 2002 potentiometer (Crison Instruments, Barcelona, Spain) and using a Schott Blueline 11-pH glass combination electrode (Schott instruments $\mathrm{GmbH}$, Mainz, Germany).

\subsection{Materials}

Formic acid, acetic acid, ammonia, ammonium monohydrogen phosphate, ammonium dihydrogen phosphate, borax, trimethylamine and ammonia-all of analytical grade or better-were employed as BGE components. Harmane, norharmane, harmalol hydrochloride dihydrate, harmine, harmol hydrochloride dihydrate and harmaline were purchased from Aldrich (Steinheim, Germany). Individual stock standard solutions of the six alkaloids were prepared by dissolving the solid in methanol up to a concentration of $1000 \mu \mathrm{g} / \mathrm{ml}$. All stock solutions were stored at $4{ }^{\circ} \mathrm{C}$. The working solutions were diluted 1:100 in water and filtered through $0.22 \mu \mathrm{m}$ membrane before use.

Solutions were prepared with water provided by a MilliQ ${ }^{\circledR}$ water purification system (Millipore, Bedford, MA, USA). Methanol was of HPLC grade (Merck, Darmstadt, Germany). The combined electrode was calibrated with the standard aqueous buffers prepared according to the NBS/NIST methods: potassium hydrogen phtalate, $\mathrm{pH}=4.000$, sodium monohydrogen phosphate/potassium dihydrogen phosphate, $\mathrm{pH}=6.881$, and borax, $\mathrm{pH}=9.225$.

Fused-silica capillaries ( $75 \mu \mathrm{m}$ i.d.), supplied by Polymicro Technologies (Phoenix, AZ, USA), were cut at a total length of $60 \mathrm{~cm}$, and an effective length of $51 \mathrm{~cm}$.

\subsection{Procedures}

New capillaries were activated by flushing at 1000 mbar with $1 \mathrm{M} \mathrm{NaOH}$ (20 min), water (15 min), and BGE (30 min). Between runs the capillary was rinsed by flushing with $0.1 \mathrm{M} \mathrm{NaOH}$ (1 min), water ( $1 \mathrm{~min})$ and BGE (5 min). Samples were hydrodynamically injected by applying 30 mbar for $3 \mathrm{~s}$, and the separation was conducted at $20 \mathrm{kV}$ (positive polarity in the inlet). The detector was set at $254 \mathrm{~nm}$.

The ionic strength of the BGEs used in this work was constant ( $25 \mathrm{mM})$. The actual mobilities $\left(\mu_{\text {act }}\right)$, those corresponding to the fully ionized species (e.g. cation $\mu_{a c t}{ }^{+}$), were determined by injecting each alkaloid spiked with a small amount of methanol used as an EOF marker. The ammonium formate BGE was set at a $\mathrm{pH}$ of 3.5 , more than $2 \mathrm{pH}$ units below the $p K_{a 1}$ of these alkaloids. All the determinations were done at $25^{\circ} \mathrm{C}$ and the values were the average of five replicates.

The determinations of $\mathrm{pK}_{a}$ were made by a nonlinear regression analysis of the experimental effective mobilities at the different
$\mathrm{pH}$ conditions. The BGEs employed were: ammonium formate $\mathrm{pH}$ 4.00, ammonium acetate $\mathrm{pH} 5.75$, ammonium hydrogen phosphate/ammonium dihydrogen phosphate $\mathrm{pH} 7.77$, borax $\mathrm{pH} 9.23$, and triethylamine $\mathrm{pH} 11.85$, all of them at total ionic strength of $25 \mathrm{mM}$.

\subsection{Data treatment} is:

The general expression for the $\mu_{\text {eff }}$ of a partially ionized analyte

$\mu_{\text {eff }}=\mu_{\text {act }} \chi=\mu_{\text {app }}-\mu_{\text {eof }}=\frac{L_{t} L_{d}}{V}\left(\frac{1}{t_{m}}-\frac{1}{t_{e o f}}\right)$

where $L_{t}$ and $L_{d}$, are the total and effective lengths, respectively, $V$ denotes the applied voltage, and $t_{m}$ and $t_{E O F}$ represent the migration and EOF times, respectively. $\chi$ is the mole fraction of the ionized form of the analyte, which depends on the $\mathrm{pH}$ of the BGE. By expressing $\chi$ as a function of the $p K_{a}$, the $\mathrm{pH}$, and the actual mobility $\left(\mu_{\text {act }}\right)$, a known theoretical equation for predicting the $\mu_{\text {eff }}$ as a function of $\mathrm{pH}$ can be obtained for cations (from compounds with basic protonable groups):

$\mu_{e f f}^{+}=\frac{\mu_{a c t}^{+}}{1+10^{\left(p H-p K_{a}\right)}}$

An equivalent expression can be obtained for anions (from compounds with acid ionizable groups):

$\mu_{\text {eff }}^{-}=\frac{\mu_{a c t}^{-}}{1+10^{\left(p K_{a}-p H\right)}}$

Harmol and harmalol have two $p K_{a}$. Therefore, the expression describing the $\mu_{\text {eff }}$ as a function of $\mathrm{pH}$ for compounds coexisting in the form of various ions can be obtained as the sum of the contributions of both the cations and the anions:

$\mu_{\text {eff }}=\mu_{e f f}^{+}+\mu_{e f f}^{-}=\frac{\mu_{a c t}^{+}}{1+10^{\left(p H-p K_{a 1}\right)}}+\frac{\mu_{a c t}^{-}}{1+10^{\left(p K_{a 2}-p H\right)}}$

These equations have been demonstrated to represent accurately the dependence of the $\mu_{\text {eff }}$ on $\mathrm{pH}$ for a wide range of ionizable compounds, including complex polyprotic substances, such as peptide hormones and small proteins $[18,19]$. Therefore, these expressions can be used to compose a multicriterion function for determining mathematically the optimal $\mathrm{pH}$ for the separation of a group of compounds.

Considering the advantages of the parameter $d_{i j}$ [25] (Eq. (5)) for characterizing the separation between a pair of compounds, as compared to other QCS such as $p_{i j}$ or $\alpha_{i j}$, and taking into account its limitations, we propose the following expression:

$t^{\prime}=\left[\mu_{\text {eff }(i)} \mu_{\text {eff }(j)}\left(\mu_{e f f(i)}-\mu_{\text {eff }(j)}\right)\right]^{2}$

The difference qualifies, per se, the separation between the two compounds, whereas the multiplication qualifies the separation between each one and the neutral compounds migrating with the EOF. The proposed parameter is squared to overcome the drawback related to changes in order or direction of migration. In order 


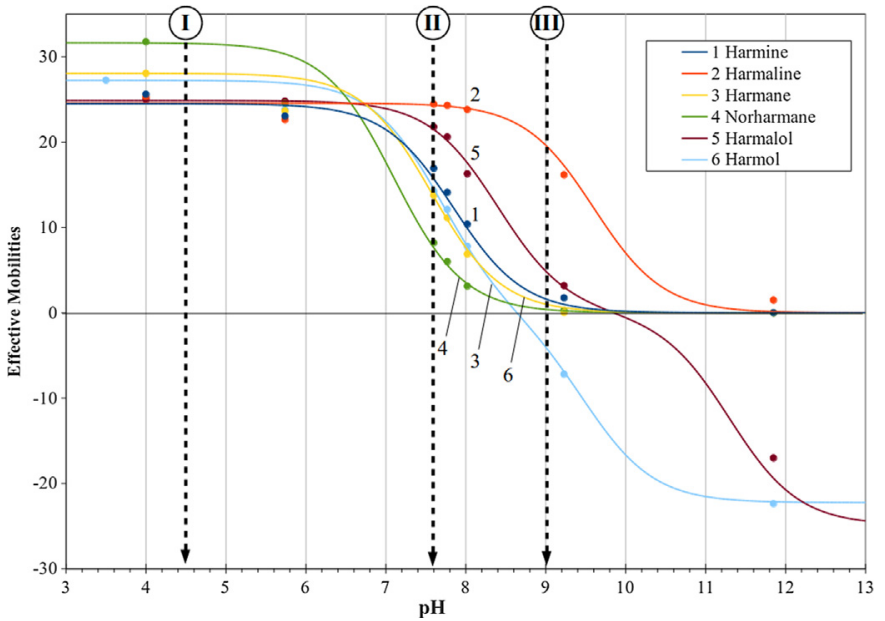

Fig. 2. Plots of effective mobility ( $\left.\mu_{\text {eff }}\right) v s$. pH of the BGE for (1) harmine, (2) harmaline, (3) harmane, (4) norharmane, (5) harmalol and (6) harmol. Lines correspond to predicted $\mu_{\text {eff }}$ values through Eqs. (7) or (9). The points correspond to experimental values. The broken lines (I, II and III) correspond to the $\mathrm{pH}$ analyzed.

to complete the procedure, the dependencies of $\mu_{\text {eff }}$ on the desired OVs (e.g., the $\mathrm{pH}$, temperature, organic solvent composition, sodium dodecyl sulfate concentration in MEKC, etc.) in Eq. (10) must be considered. The resulting expression has the attributes of being always positive and continuous, and the mathematical maximization neither tends towards undesired values nor requires imposing arbitrary restrictions.

This definition can be extended to compose, as a single equation, a multicriterion function which is not the simple product of $t^{\prime}$ parameters, for characterizing the separation of $n$ compounds: and number of ionizable groups of each HAlk molecule to obtain the results listed in Table 1 . Even though those $p K_{\mathrm{a}}$ determinations were not the principal aim of this work, the data obtained have very good agreement with values reported in literature [26-29]. Several authors have demonstrated that these plots can provide valuable information about $\mu_{e f f}$ for calculating classical $Q C s\left(d_{i j}\right.$ and $\alpha_{i j}$ ) and, finally, to obtain optimum pHs for the separation of mixtures of compounds $[15,25]$. However, in fused silica capillaries the EOF is associated with a significant variability and is also strongly dependent on conditions such as $\mathrm{pH}$, buffer nature and concentration, and ionic strength. Therefore, $\mathrm{pH}$ optimizations based on those classical QCs that do not take the EOF into account result in poor reproducibility. In order to compare the criterion proposed here, $t$ ', with the two aforementioned classic QCs, we optimized the $\mathrm{pH}$ value for the separation of the six HAlks based on all three criteria. In order to simplify the analysis, we first showed a graphical multicriterion method. We explored specifically $\alpha_{i j}$, $d_{i j}$ or $t_{i j^{\prime}}$ for all possible pairs of compounds within the mixture represented as overlapping maps or windows diagrams [31-34]. These graphs (Fig. 3) are very useful for our purposes. Each plot represents an overlap of the $Q C$ behavior for all the pairs of compounds. Since $\mu_{\text {eff }}$ can be predicted within the full pH range from the corresponding Eqs. (7), (8) or (9) along with the experimental $\mu_{a c t}$ and $p K_{a}$ data for each compound, then, the required $\alpha_{i j}, d_{i j}$ or $t_{i j}$ can be calculated as a function of the

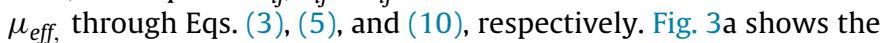
optimization maps based on $\alpha_{i j}$ as a function of $\mathrm{pH}$; the areas in black indicate more clearly the optimization boundaries. The black zones delimits the hardest-to-separate pair at a corresponding $\mathrm{pH}$. It must be noted that the lowest $\alpha_{i j}$ value on Fig. 3a, is 1.0. Thus, the arrival of any black zone at that value indicates a $\mathrm{pH}$ zone where

$T^{\prime}=\left[\left(\mu_{1} \mu_{2} \mu_{3} \ldots \mu_{n}\right)\left(\left(\mu_{1}-\mu_{2}\right)\left(\mu_{1}-\mu_{3}\right) \ldots\left(\mu_{1}-\mu_{n}\right) \ldots\left(\mu_{(n-1)}-\mu_{n}\right)\right)\right]^{2}=\left[\left(\prod_{i=1}^{n} \mu_{i}\right)\left(\prod_{(i, j)(j<i)}^{n,(n-1)} \Delta \mu_{(i, j)}\right)\right]^{2}$

where all $\mu$ indicate $\mu_{\text {eff }}$ but, for the sake of simplicity, the subscripts "eff" have been omitted.

\section{Results and discussion}

Fig. 1 and Table 1 summarize the structure and relevant properties of the different HAlks. The six compounds are structurally similar, having a $\beta$-carboline core, with different substituents and the presence or absence of unsaturation in one $\mathrm{C}-\mathrm{C}$ bond (i.e., between C3 and C4 in harmine-harmaline and harmol-harmalol, respectively). As a consequence, the six have only slight differences in molecular mass ( $\sim 0.7 \%)$, hydrodynamic size and acid dissociation constants. The first $p K_{a}$ values $\left(p K_{\mathrm{a} 1}\right)$ range from 7.10 to 9.60 and correspond to the dissociation of the protonated pyridinium moiety (Fig. 1). Harmol and harmalol have a phenolic group with $p K_{\mathrm{a} 2}$ values of 9.52 and 11.3 , respectively. Therefore, since electrophoretic migration is related directly to the charge-to-radius ratio (or charge-to-mass ratio) at a certain $\mathrm{pH}$ value, the optimization of separation as a function of $\mathrm{pH}$ will be an intensive labor involving trial an error experiments.

Fig. 2 depicts the behavior of $\mu_{\text {eff }}$ with $\mathrm{pH}$ for all the HAlks. In the figure, the continuous lines indicate the $\mu_{e f f}$ of each HAlk calculated on the basis of the corresponding expressions, Eq. (7), (8) or (9), as a function of the $p K_{\mathrm{a}}$ values shown in Table 1 ; whereas the circles are experimental values obtained from CE separations carried out at the corresponding $\mathrm{pH}$ values. In this case, expressions describing the dependencies $\mu_{\text {eff }} v s$. $\mathrm{pH}$ have been obtained on the basis of Eq. (9)-it used first to determine the $p K_{\mathrm{a}}$ values of the ionizable compounds analyzed [30]. The calculations took into account the type an inversion in the order of peak occurs, which precise point corresponds to a $\mathrm{pH}$ value where co-migration occurs. Those values correspond to points that have dropped down to the $\mathrm{x}$-axis in plots 3-b and 3-c, with the difference being that the y-axis in both plots corresponds to zero since both QCs are based on mobility differences $\left(d_{i j}\right.$ and $\left.t_{i j}\right)$. These $\mathrm{pH}$ values for coelution can be verified in Fig. 2. It must be noted that on either side of these $\mathrm{pH}$ values different definitions of the $Q C$ must be used to allow the depiction of the windows diagram-e.g., cf. in Fig. 2, harmane (curve 3) and norharmane (curve 4 ) for $\mathrm{pH}<6.5$ is defined $\alpha_{43}=\mu_{4} / \mu_{3}$ while for $\mathrm{pH}>6.5$ the definition changes to $\alpha_{34}=\mu_{3} / \mu_{4}$. By analyzing the $\mathrm{pH}$ range between 7 and 8 , the critical pair is harmane-harmol (curves 3 and 6). This optimization range is narrow and is somewhat less than $0.5 \mathrm{pH}$ units around the maximum in Fig. 3. Therefore, the $p K_{a}$ values must be exact because small deviations from the real value may involve a huge change in the optimization prediction. Fig. 3a shows other $\mathrm{pH}$ values with greater $\alpha_{i j}$ values in the $\mathrm{pH}$ range between 8.0 and 13.0. The $\alpha_{\mathrm{ij}}$ values though, can be maximized at the expense of minimizing the ionization of the slower analyte of a given pair and, as a consequence, $\alpha_{\mathrm{ij}}$ approaches to infinite. In such a case, a separation of the HAlks from the neutral compounds becomes theoretically impossible, as will be confirmed experimentally ( $c f$. below). Similar information might be obtained from Fig. 3b that shows the maps of $d_{i j}\left(\Delta \mu_{i j}\right)$ as a function of $\mathrm{pH}$. The critical pairs are the same but, in this case, the optimal $\mathrm{pH}$ region now only extends from 8.0 to 10.0 . This reduction occurs because $d_{i j}$ was not maximized when the compounds migrated with the neutral compounds and the EOF. Again, the best separation is obtained 


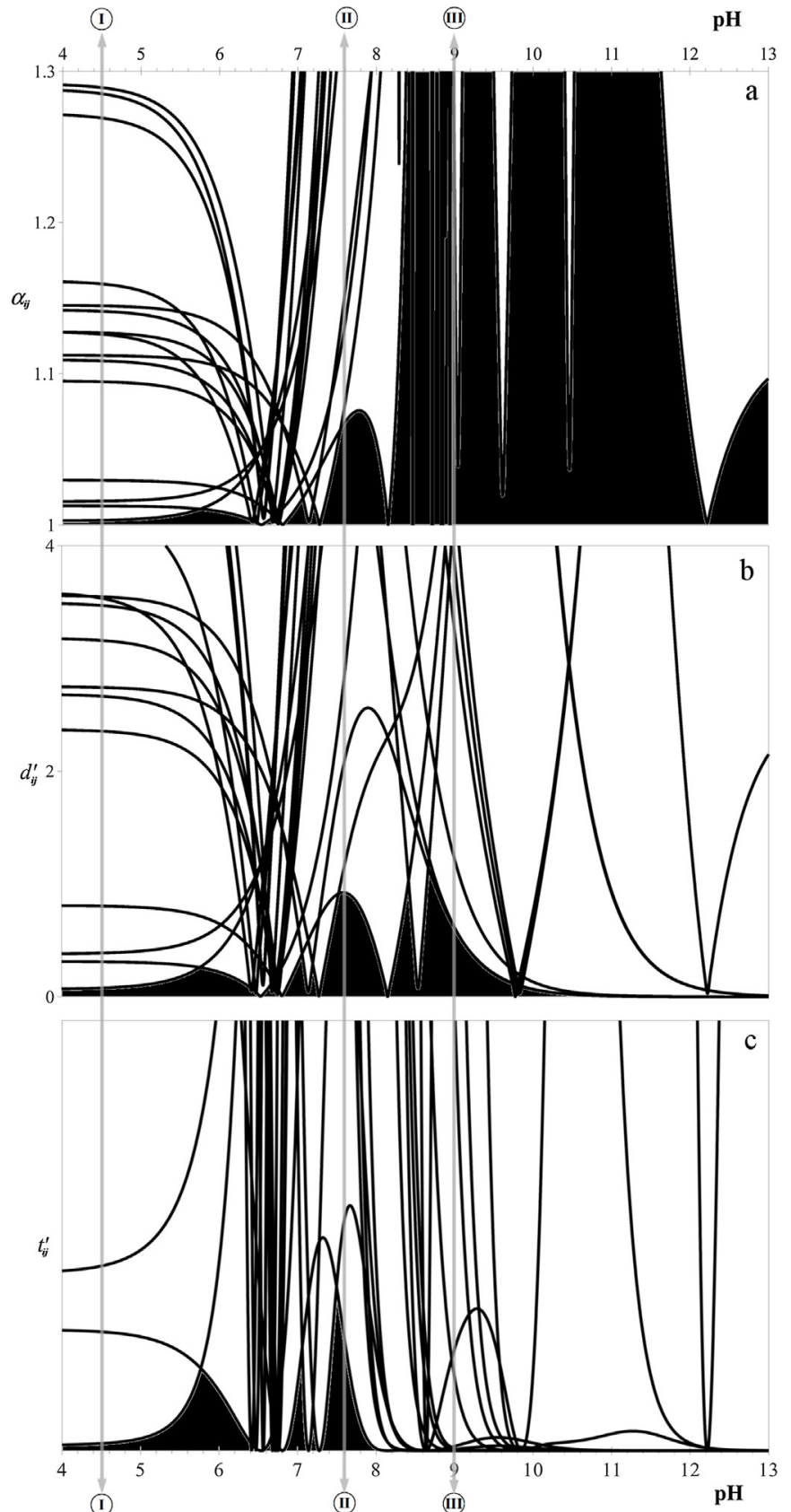

Fig. 3. Plots of (a) selectivity $\alpha_{i j}$, (b) $\Delta \mu_{\text {effij }} \quad\left(d_{i j}\right)$ and (c) $t_{i j} \hat{\imath}$ $=\left[\left(\mu_{\text {eff }, i}-\mu_{\text {eff }, j}\right) \mu_{\text {eff }, i} \cdot \mu_{\text {eff }, j}\right]^{2}$ for the six HAlks as a function of $\mathrm{pH}$ of the BGE. (1) harmine, (2) harmaline, (3) harmane, (4) norharmane, (5) harmalol, (6) harmol. In vertical red lines are indicated experimental pHs corresponding to the electropherograms obtained below.

in the $\mathrm{pH}$ range $7.0-8.0$. Furthermore, in the lower $\mathrm{pH}$ region $(\mathrm{pH}$ 4.0-6.0), the 1-6 pair can also be identified as the hardest to separate. Fig. $3 c$ depicts the optimization maps of $t_{i j}{ }^{\prime}$ as a function of $\mathrm{pH}$. In these plots, low tí values do not necessarily indicate a poor separation between analytes but also signify an insufficient separation between one of them and the neutral compounds migrating with the EOF. Once again, the pairs harmine-harmol (curves 1 and 6 in Fig. 2, respectively) and harmane-harmol (curves 3 and 6 ) were the hardest to separate within the $\mathrm{pH}$ range 7.0-8.0, which is the optimum separation conditions. Another maximum of $t_{i j}$ ' occurs at around $\mathrm{pH}=6.5$, but that $\mathrm{pH}$ range is extremely narrow (about 0.1

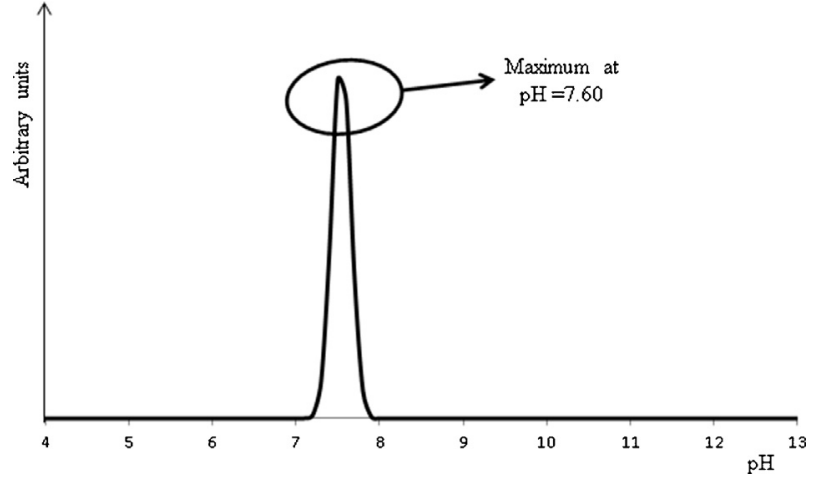

Fig. 4. Plot of the multicriterion function Tí with $t_{i j} i$ as qualification criterion $(Q C)$ as a function of $\mathrm{pH}$ for optimization of the separation of the six HAlks.

units), hence less convenient in practice. In contrast, no other $\mathrm{pH}$ region, at more basic $\mathrm{pH}$ is detected by the $t_{i j}$ ' parameter.

These previous analysis-made on the basis of overlapping maps, thus overcoming the problem of the change in the migration order through using different definitions of the $Q C$-have the purpose of visualizing more clearly the particular drawbacks of the classic parameters. The proper method for optimizing the separation of multiple compounds on the basis of the criterion $t_{i j}$, however, is to compose the multicriterion optimization function $t_{i j}$. Fig. 4 shows a plot of this multicriterion function $\left(t_{i j}{ }^{\prime}\right)$ calculated from Eq. (11). To draw conclusions from this plot, where a clear maximum was observed at $\mathrm{pH}$ 7.6, was extremely easy. At this $\mathrm{pH}$ value, the best separation between the six analytes and from the neutral compounds migrating with the EOF is theoretically achieved. Furthermore, it can be assumed that separation is possible only within a short $\mathrm{pH}$ range between $\mathrm{pH} 7.4$ and 8.0. Once the optimum theoretical pH was established by using the general function, a few experimental separations within a short $\mathrm{pH}$ range around this optimum theoretical value were performed in order to validate the results. Since the optimized $\mathrm{pH}$ is related to the accuracy of $p K_{\mathrm{a}}$ values and the precision of the $\mathrm{pH}$ measurement, an optimization around $\pm 0.3 \mathrm{pH}$ units from the optimum theoretical $\mathrm{pH}$ value is strongly recommended.

Fig. 5a shows the electropherogram under the $\mathrm{pH}$ conditions more frequently used to analyze molecules containing amino functional groups positively charged. This approach can be successful only if considerable differences exist in the molecular weights between the analytes. For this harmala mixture, a total separation between norharmane and harmane can be achieved, but leaving the harmalol-harmol and harmaline-harmine pairs only partially separated, in clear agreement with the smaller tí values observed in Fig. 3c. In the $\mathrm{pH}$ range between $\mathrm{pH} 1$ to 6.5 with a maximum at $\mathrm{pH} 5.8, t^{\prime}$ indicates a second relative maximum along with potential separation there; but a poor efficiency prevented an acceptable separation of harmaline, harmine and harmalol, as can be inferred from Fig. 2. The optimum $\mathrm{pH}$ region is similar to that obtained by means of $d_{i j}$ and $\alpha_{i j}$ in plots 3-a and 3-b, respectively. In addition, Fig. 5b shows the separation of the six alkaloids under optimal pH conditions ( $\mathrm{pH}=7.6$ ). It must be noted that optimal separation illustrated in the electropherogram at $\mathrm{pH} 7.6$ (Fig. 5b) is an absolute maximum according to both, tí (Fig. 3c) and Tí (Fig. 4); whereas, using $d_{i j}$ parameter, this $\mathrm{pH}$ region corresponds to a relative maximum. With respect to $\alpha_{i j}$, and according to the window diagram shown in Fig. 3a, this pH should be selected as the third most relevant. In Fig. 5c, we show an electropherogram of the six HAlks analyzed at $\mathrm{pH}$ 9.0. This condition represents a maximum separation if we evaluate the system under the $d_{i j}$ and $\alpha_{i j}$ parameters. In contrast, the analysis with respect to tí indicates this $\mathrm{pH}$ range as a zone of poor separation. A comparison of the results obtained theoretically with 



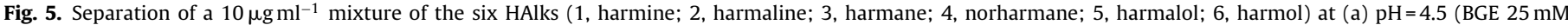

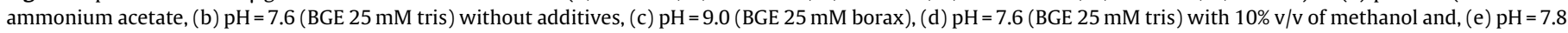

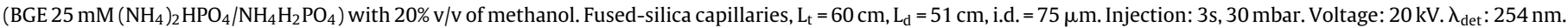

the experimental electropherogram (Fig. 5c) indicates that these results are in perfect agreement with the $t$ ' prediction. The drawbacks of $d_{i j}$ and $\alpha_{i j}$ consist in the maximization of the $Q C$ function when the mobility of one of the analytes approaches zero, as seen with the co-migration of harmine, harmol and harmaline with the EOF marker.

A comparative analysis of the experimental results obtained at the $\mathrm{pH}$ values indicated as optimum based on $\alpha_{i j}, d_{i j}$ and $t_{i j}^{\prime}$ proves that our criterion correctly predicts the optimum $\mathrm{pH}$ for separation. As mentioned above, parameters based on migrations when used in predictive models do not take into account the separation efficiency. Our criterion is not immune to this problem. At the $\mathrm{pH}$ value optimized by means of our proposed criterion, the best possible separation is obtained in terms of peak tops. All the migrations are acceptable and well separated from neutral compounds, but the peaks are not baseline resolved because of their shapes, at least for harmine and harmol. Although not the main objective of the present work, we will propose how to continue the optimization of these analytes. In a previous publication, we demonstrated that the peak shape and efficiency for separation of these alkaloids could be improved by adding $20 \%$ (v/v) of methanol to this same BGE [35]. The electropherograms obtained when methanol is added at levels of $10 \%$ and $20 \%$ by volume are depicted in Fig. $5 \mathrm{~d}$ and e. The results demonstrate that the addition of organic solvents to the BGE dramatically improves the separation efficiency. For that purpose, we strongly recommend first making a theoretical optimization of the $\mathrm{pH}$ condition, and then optimizing the discontinuous variables such as the organic solvents or other additives.

In summary, the experimental electropherograms agreed perfectly with the results expected from the maps of $t_{i j}{ }^{\prime}$ (Fig. 3c) and the plot of the multicriterion function (Tí) (Fig. 4). In contrast to the excellent accuracy in the prediction of separations through $t^{\prime}$ plots, the experimental results contradicted the optimal $\mathrm{pH}$ range
$(\mathrm{pH}=9)$ when $\alpha_{\mathrm{ij}}$ or $d_{i j}$ maps were evaluated (Fig. 3a and b). These QCs failed because the separation from neutral compounds was not duly considered.

\section{Conclusions}

A novel quality criterion, $Q C$, for characterizing the separation of compounds in CE was proposed. The elementary form of this criterion, $t$ ', takes into account the relative separation between a given pair of compounds and also their separation from the neutral species present in real samples. On the basis of this $Q C$, we were able to compose a multicriterion function to optimize the separation of components of a complex mixture simply and rapidly.

As an example of these principles, the separation of six structurally related alkaloids was optimized as a function of $\mathrm{pH}$. In this case, the $\mu_{\text {eff }}$ of the six analytes could be accurately predicted through well-known functions describing the dependencies of the mobilities on $\mathrm{pH}$. The results obtained demonstrated the advantages of using the criterion t', instead of $\alpha_{i j}$ or $d_{i j}$ to optimize the $\mathrm{pH}$ in a CE separation, especially when analyzing real samples containing a large number of neutral compounds. This optimization has low requirements because only the $p K_{\mathrm{a}}$ values and the mobility of the fully ionized forms (i.e., actual mobilities) of the different components are needed, which in the worst possible scenario could be determined from the results of only a few experiments. Furthermore, the mathematical expressions are considerably simple and do not require any special calculation software or limiting conditions. The proposed $Q C$ and the derived multicriterion functions can be extended to electroseparation modes such as MEKC or CEC, but also to any other field of application where the differences between certain factors have to be maximized but without becoming zero. 


\section{Acknowledgements}

Marcos Tascon acknowledges the ANPCyT-Universidad Nacional de la Plata for a PFDT fellowship. This study was supported by CONICET in Argentina, and the Spanish Ministry of Education and Science in Spain. Dr. Donald F. Haggerty, a retired academic career investigator and native English speaker, edited the final version of the manuscript.

\section{References}

[1] P.J. Schoenmakers, Optimization of Chromatographic Selectivity, Elsevier, Amsterdam, The Netherlands, 1986

[2] D. Heiger, High-performance capillary electrophoresis, Agilent (2000), http:// dx.doi.org/10.1039/9781847550521-00208.

[3] S.C. Beale, S.F. Li, C.J. Evenhuis, R.M. Guijt, M. Macka, P.J. Marriott, P.R. Haddad, Capillary Electrophoresis, Elsevier, Amsterdam, The Netherlands, 1993.

[4] S.C. Beale, Capillary electrophoresis, Anal. Chem. (1998) 279R-300R.

[5] J.W. Jorgenson, K.D. Lukacs, Zone electrophoresis in open-tubular glass capillaries, Anal. Chem. 53 (1981) 1298-1302.

[6] Y.Y. Rawjee, D.U. Staerk, G. Vigh, Capillary electrophoretic chiral separations with cyclodextrin additives I. Acids: chiral selectivity as a function of $\mathrm{pH}$ and the concentration of $p$-cyclodextrin for fenoprofen and ibuprofen, J. Chromatogr. 635 (1993) 291-306.

[7] N. Chen, L. Wang, Y. Zhang, Electrophoretic selectivity as a function of operating parameters in free-solution capillary electrophoretic separation of dipeptides, J. Liq. Chromatogr. 16 (1993) 3609-3622, http://dx.doi.org/10. 1080/10826079308019656.

[8] G.M. Janini, K.C. Chan, G.M. Muschik, H.J. Issaq, Optimization of resolution in capillary zone electrophoresis: effect of solute mobility and buffer pH, J. Liq. Chromatogr. 16 (1993) 3591-3607, http://dx.doi.org/10.1080/ 10826079308019655.

[9] A.M. Siouffi, R. Phan-Tan-Luu, Optimization methods in chromatography and capillary electrophoresis, J. Chromatogr. A 892 (2000) 75-106 http://www ncbi.nlm.nih.gov/pubmed/11045482.

[10] S. Orlandini, R. Gotti, S. Furlanetto, Multivariate optimization of capillary electrophoresis methods: a critical review, J. Pharm. Biomed. Anal. 87 (2014) 290-307, http://dx.doi.org/10.1016/j.jpba.2013.04.014.

[11] L.R. Snyder, J.W. Dolan, D.C. Lommen, Drylab computer simulation for high-performance liquid chromatographic method development, J. Chromatogr. 485 (1989) 65-89.

[12] J.W. Dolan, D.C. Lommen, L.R. Snyder, Drylab computer simulation for high performance liquid chromatographic method development, J. Chromatogr 485 (1989) 91-112.

[13] Molnar Imre, Computerized design of separation strategies by reversed-phase liquid chromatography: development of DryLab software, J. Chromatogr. A 965 (2002) 175-194.

[14] Y. Dharmadi, R. Gonzalez, A better global resolution function and a novel iterative stochastic search method for optimization of high-performance liquid chromatographic separation, J. Chromatogr. A 1070 (2005) 89-101, http://dx.doi.org/10.1016/j.chroma.2005.02.075.

[15] V. Dolník, Selectivity, differential mobility and resolution as parameters to optimize capillary electrophoretic separation, J. Chromatogr. A 744 (1996) $115-121$.

[16] P. Gebauer, P. Boček, Optimization in isotachophoresis, J. Chromatogr. A 320 (1985) 49-65.

[17] M. Castagnola, D.V. Rossetti, M. Corda, M. Pellegrini, F. Misiti, A. Olianas, B. Giardina, I. Messana, The $\mathrm{pH}$ dependence of predictive models relating electrophoretic mobility to peptide chemico-physical properties in capillary zone electrophoresis, Electrophoresis 19 (1998) 2273-2277, http://dx.doi.org/ 10.1002/elps.1150191304.
[18] F. Benavente, E. Balaguer, J. Barbosa, V. Sanz-Nebot, Modelling migration behavior of peptide hormones in capillary electrophoresis-electrospray mass spectrometry, J. Chromatogr. A 1117 (2006) 94-102, http://dx.doi.org/10. 1016/j.chroma.2006.03.049.

[19] F. Benavente, E. Giménez, D. Barrón, J. Barbosa, V. Sanz-Nebot, Modeling the electrophoretic behavior of quinolones in aqueous and hydroorganic media, Electrophoresis 31 (2010) 965-972, http://dx.doi.org/10.1002/elps. 200900344.

[20] J.C. Giddings, Generation of variance, theoretical plates, resolution, and peak capacity in electrophoresis and sedimentation, Sep. Sci. 4 (1969) 181-189, http://dx.doi.org/10.1080/01496396908052249.

[21] B.J. Wanders, T.A.A.M. van de Goor, F.M. Everaerts, On-line measurement of electroosmosis in capillary electrophoresis using a conductivity cell, J. Chromatogr. A 652 (1993) 291-294, http://dx.doi.org/10.1016/00219673(93)80671-T.

[22] C. Schwer, E. Kenndler, Electrophoresis in fused-silica capillaries: the influence of organic solvents on the electroosmotic velocity and the zeta potential, Anal. Chem. 63 (1991) 1801-1807, http://dx.doi.org/10.1021/ ac00017a026.

[23] M.T. Galceran, L. Puignou, M. Diez, Comparison of different electroosmotic flow modifiers in the analysis of inorganic anions by capillary electrophoresis, J. Chromatogr. A 732 (1996) 167-174, http://dx.doi.org/10.1016/00219673(95)01248-6.

[24] C.J. Evenhuis, R.M. Guijt, M. Macka, P.J. Marriott, P.R. Haddad, Variation of zeta-potential with temperature in fused-silica capillaries used for capillary electrophoresis, Electrophoresis 27 (2006) 672-676, http://dx.doi.org/10. 1002/elps.200500566.

[25] B.K. Clark, C.L. Nickles, K.C. Morton, J. Kovac, M.J. Sepaniak, Rapid separation of DNA restriction digests using size selective capillary electrophoresis with application to DNA fingerprinting, J. Microcolumn Sep. 6 (1994) 503-513, http://dx.doi.org/10.1002/mcs.1220060510.

[26] K.T. Douglas, R.S. Sharma, J.F. Walmsley, R.C. Hider, Ionization processes of some harmala alkaloids, Mol. Pharmacol. 23 (1983) 614-618.

[27] D.D. Perrin, The dissociation constants of perlolidene and harmol, N. Z. J. Sci. Technol. 388 (1957) 688-694.

[28] M. Balón, J. Hidalgo, P. Guardado, M.A. Muñoz, C. Carmona, Acid-base and spectral properties of b-carbolines. Part 2. Dehydro and fully aromatic b-carbolines, J. Chem. Soc. Perkin Trans. 2 (2) (1993) 99-104, http://dx.doi. org/10.1039/p29930000099.

[29] S.D. Mendonsa, R.J. Hurtubise, Determination of ionization constants of heterocyclic aromatic amines using capillary zone electrophoresis, J. Chromatogr. A 841 (1999) 239-247.

[30] G.A. Caliaro, C.A. Herbots, Determination of pKa values of basic new drug substances by CE, J. Pharm. Biomed. Anal. 26 (2001) 427-434

[31] R.J. Laub, J.H. Purnell, Criteria for the use of mixed solvents in gas-liquid chromatography, J. Chromatogr. 112 (1975) 71-79.

[32] R.J. Laub, J.H. Purnell, P.S. Wlliams, Computer-assisted prediction of gas chromatographic separations, J. Chromatogr. 134 (1977) 249-261.

[33] R.J. Laub, J.H. Purnell, Quantitative optimization of system variables for chromatographic separations, J. Chromatogr. Sci. 161 (1978) 49-57.

[34] J.L. Glajch, J.J. Kirkland, K.M. Squire, Optimization of solvent strength and selectivity for reversed-phase liquid chromatography using an interactive mixture-design statistical technique, J. Chromatogr. 199 (1980) 57-79.

[35] M. Tascón, F. Benavente, N.M. Vizioli, L.G. Gagliardi, A rapid and simple method for the determination of psychoactive alkaloids by CE-UV: application to Peganum harmala seed infusions, Drug Test Anal. (2016), http://dx.doi.org/10.1002/dta.1989 (in press). 